\title{
Representasi Stereotip Etnis Tionghoa dalam Iklan Bukalapak Edisi Imlek
}

\author{
Salma Safira Salsabila (Penulis Korespondensi) \\ Program Studi Ilmu Komunikasi, Universitas Muhammadiyah Yogyakarta, Indonesia \\ salmasafira59@gmail.com \\ Fara Afwa Nasikha \\ Program Studi Ilmu Komunikasi, Universitas Muhammadiyah Yogyakarta, Indonesia \\ faraafwanasikha@gmail.com \\ Maudy Aulia Putri \\ Program Studi Ilmu Komunikasi, Universitas Muhammadiyah Yogyakarta, Indonesia \\ maudyaulia2@gmail.com \\ Diserahkan: 05 Mei 2020; Direvisi: 06 Oktober 2020; Diterima: 10 Oktober 2020
}

\begin{abstract}
Advertising is a form of paid communication about an organization, product, service or idea by an identified sponsor. Advertisements are created to receive prompt feedback from message recipients. To fulfill quick feedback, Bukalapak created an advertisement featuring Chinese ethnic culture as a tool to attract the attention of message recipients. This study was designed to analyze stereotypes in the Chinese edition of Bukalapak advertisement. The research method used is a qualitative descriptive method with Roland Barthes' semiotic analysis techniques. The analysis was carried out by looking at the signs used in the Chinese New Year edition of Bukalapak advertisement 2017. The findings of this study show that the Imlek edition of Bukalapak advertisements contains Chinese ethnic stereotypes.

Keywords: Bukalapak, Imlek, Stereotype, Tionghoa
\end{abstract}

\section{Abstrak}

Iklan merupakan bentuk komunikasi berbayar tentang suatu organisasi, produk, servis, atau ide oleh sponsor yang diidentifikasi. Iklan dibuat untuk menerima timbal balik yang cepat dari penerima pesan. Untuk memenuhi timbal balik yang cepat, Bukalapak membuat iklan dengan menampilkan budaya etnis Tionghoa sebagai alat untuk menarik perhatian penerima pesan. Penelitian ini dirancang untuk menganalisis stereotip dalam iklan Bukalapak edisi Imlek. Adapun metode penelitian yang digunakan adalah metode deskriptif kualitatif dengan teknik analisis semiotika Roland Barthes. Analisis yang dilakukan yaitu dengan melihat tanda-tanda yang digunakan dalam iklan Bukalapak edisi Imlek tahun 2017. Temuan penelitian menunjukan bahwa iklan Bukalapak edisi Imlek mengandung stereotip etnis Tionghoa.

Kata Kunci: Bukalapak, Imlek, Stereotip, Tionghoa

\section{PENDAHULUAN}

Perkembangan zaman yang begitu pesat menyebabkan adanya peningkatan pertukaran informasi secara global di bidang teknologi, ekonomi, maupun politik. Faktanya, perkembangan dalam bidang ekonomi telah menyebabkan banyaknya kemunculan produk baru ataupun jasa yang beraneka ragam. Kemunculan produk baru ataupun jasa memiliki dampak negatif maupun positif. Dampak positif dari menjamurnya iklan adalah tersedianya berbagai alternatif produk atau jasa pilihan. Sementara itu, dampak negatif iklan yaitu munculnya kesulitan untuk memilih produk atau jasa yang kita butuhkan atau inginkan. Menyadari dilema tersebut, produsen produk baru atau jasa akan berlomba-lomba menyajikan iklan dengan memaparkan informasi terkait produk atau jasa guna menarik perhatian publik. Di titik ini, peran iklan hadir untuk memenangkan persaingan dalam memperebutkan konsumen.

Saat ini iklan tidak hanya ditujukan untuk menarik perhatian semata, persaingan yang ketat telah menjadikan iklan memiliki muatan konflik khususnya dalam kehidupan sosial kebudayaan. Informasi- 
informasi yang terkandung dalam iklan dapat memiliki arti yang berbeda-beda bagi setiap orang yang menilainya. Bukalapak merupakan satu dari sekian banyak situs jual beli online yang ada di Indonesia. Bukalapak sendiri didirikan sejak tahun 2010 oleh tiga mahasiswa asal Institut Teknologi Bandung. Sejak 2017 Bukalapak melebarkan sayapnya dengan program Mitra Bukalapak, penjual offline atau mitra warung. Penjual yang tergabung dalam Bukalapak hingga Oktober 2019 telah mencapai dua juta mitra warung dan individu. Hingga pada Januari 2017, sehubungan dengan Imlek, Bukalapak membuat kampanye nego cincai untuk memperkenalkan fitur tawar-menawar layaknya di pasar tradisional ke dalam platform digital.

Kampanye nego cincai merupakan perpanjangan dari kampanye hari belanja online nasional 2016 karena dinilai berhasil menyumbang trafik di Bukalapak (Triwijanarko, 2018). Namun demikian, apabila dilihat dari sisi yang berlainan, iklan Bukalapak edisi Imlek tersebut menggambarkan stereotip etnis tertentu. Hal tersebut ditunjukkan dengan visualisasi pintu berwarna merah bergaya khas etnis Tionghoa, lampion, tokoh perempuan yang mengenakan pakaian berwarna merah yang kental kaitannya dengan Imlek, serta nada pengucapan jingle yang dibawakan oleh tokoh perempuan. Berangkat dari fenomena tersebut, penelitian ini dimaksudkan untuk mengetahui bagaimana representasi stereotip etnis Tionghoa dalam iklan Bukalapak edisi Imlek.

\section{KERANGKA TEORI}

\section{REPRESENTASI DAN STEREOTIP}

Representasi berarti penggunaan bahasa untuk mengatakan sesuatu yang bermakna, atau untuk menjelaskan makna dunia kepada orang lain. Namun demikian, representasi tidak hanya sebatas itu, representasi merupakan bagian terpenting dari proses dimana makna yang diproduksi dipertukarkan antar anggota suatu budaya. Merepresentasikan sesuatu berarti menyebutkan kembali dengan deskripsi jelas atau penggambaran dengan imajinasi untuk penyebutan yang mirip dengan sebelumnya. Representasi juga berarti melambangkan atau untuk pengganti (Wardle, 1999).

Dalam hal ini, stereotip mengacu pada keyakinan bahwa individu pada suatu kelompok umumnya memiliki satu atau lebih ciri maupun perilaku. Orang-orang menggunakan stereotip untuk menjelaskan perilaku mereka sendiri ataupun perilaku orang lain guna membenarkan tindakan, memutuskan bagaimana tindakan serta untuk mendefinisikan batasan kelompok. Namun demikian, masih banyak orang yang menggunakan stereotip yang buruk terhadap etnis di luar etnisnya. Padahal apabila stereotip yang dilabelkan kepada etnis lain tersebut tidak akurat, hal tersebut dapat menjadi sebuah ancaman (Kay, Matuszek \& Munson, 2015).

\section{SEMIOTIKA}

Semiotika meneliti tentang tanda (sign) yang terdiri dari dua aspek, yaitu penanda (signifier), dan petanda (signified). Penanda dapat dimengerti sebagai bentuk/wujud fisik. Penanda dapat berupa bunyi, gambar, huruf, visual, dan sejenisnya. Sedangkan petanda adalah konsep atau arti dari apa yang ditandai. Keduanya memiliki relasi yaitu bersifat "diada-adakan" yang berarti tidak terdapat relasi yang sifatnya alamiah antara penanda dan petanda. Namun demikian, relasi yang bersifat "diada-adakan" tersebut terikat oleh konvensi atau struktur. Secara etimologis, Saussure menyebutkan bahwa semiotika sebagai ilmu yang mengkaji tentang tanda sebagai bagian dari kehidupan sosial (Piliang, 2003). Semiotika kemudian dielaborasi sebagai hubungan tripartit yakni tanda (sign) yang merupakan gabungan dari penanda (signifier) dan petanda (signified) (Fiske \& Hartley, 1996).

Pemikiran Saussure tersebut kemudian dikembangkan oleh Roland Barthes dengan memberi telaah pada interaksi antara teks dengan pengalaman personal dan kultural penggunanya. Gagasan Barthes ini 
dikenal dengan tatanan penandaan (order of signification), yang mencakup primary signification atau denotasi (makna sebenarnya sesuai kamus) dan secondary signification atau konotasi (makna ganda yang lahir dari pengalaman kultural dan personal). Makna konotasi inilah yang kemudian berkembang menjadi mitos. Dalam penelitian ini, penulis berusaha melakukan analisis semiotika, mulai dari primary signification hingga secondary signification pada iklan Bukalapak versi Imlek.

\begin{tabular}{c|c}
\hline $\begin{array}{c}\text { Signifier } \\
\text { (Penanda) }\end{array}$ & $\begin{array}{c}\text { Signified } \\
\text { (Petanda) }\end{array}$ \\
\hline \multicolumn{2}{c|}{$\begin{array}{c}\text { Denotatif Sign } \\
\text { (Tanda Denotatif) }\end{array}$} \\
\hline \multicolumn{2}{c}{$\begin{array}{c}\text { Connotatif Signifier } \\
\text { (Penanda Konotatif) }\end{array}$} \\
Connotatif Signified Sign \\
(Tanda Konotatif) \\
\hline
\end{tabular}

Gambar 1. Pemaknaan tanda dalam semiotika Roland Barthes (Sobur, 2004)

\section{METODE PENELITIAN}

Dalam penelitian ini, jenis penelitian yang digunakan adalah penelitian deskriptif kualitatif dengan paradigma kritis. Secara operasional, penelitian ini menggunakan metode semiotika untuk menganalisis objek penelitian, yaitu iklan. Iklan tersebut menampilkan gambaran etnis Tionghoa yang dapat dilihat dari simbol-simbol yang ditampilkan pada iklan Bukalapak. Adapun objek penelitian dianalisis dengan menggunakan teknik analisis semiotika Roland Barthes.

\section{HASIL DAN PEMBAHASAN}

Iklan merupakan sarana komunikasi terhadap suatu produk yang ingin disampaikan melalui berbagai media dengan biaya pemrakasa agar masyarakat tertarik untuk menyetujui dan mengikuti (Lukitaningsih, 2013). Seperti dalam iklan Bukalapak edisi Imlek, pihak pengiklan bermaksud menyampaikan informasi produk mereka dengan cara membuat iklan di televisi. Dalam hal ini, iklan Bukalapak edisi Imlek teridentifikasi menggunakan tanda-tanda yang erat kaitannya dengan etnis tertentu.

Tanda-tanda yang ditangkap oleh penulis dalam iklan Bukalapak adalah adanya penggunaan unsur budaya etnis Tionghoa, diawali dengan penggunaan tokoh perempuan paruh baya yang mengenakan pakaian merah bercorak unggas berwarna keemasan serta pengriting rambut yang masih terpasang di rambutnya. Tokoh ini diapit dengan bunga sakura bermekaran dengan latar berupa pintu berwarna merah bergaris keemasan atau pintu khas Tionghoa. Di atas pintu geser tergantung lampu-lampu yang sering dipasang ketika menjelang Imlek. Lampu-lampu terebut memiliki warna merah dan emas, berbentuk tabung dengan bagian bawah terdapat rumbai-rumbai berwarna kuning keemasan. 


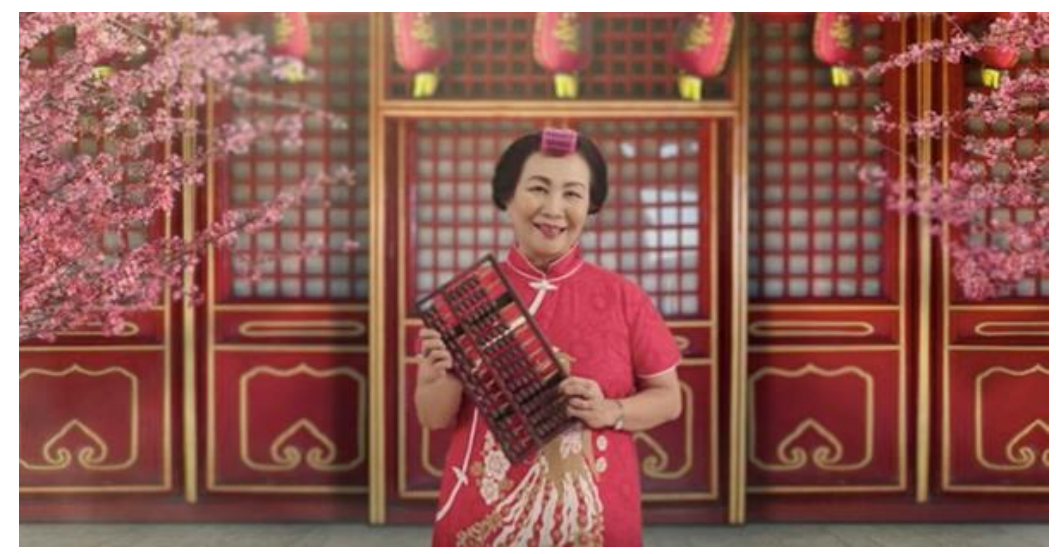

Gambar 2. Adegan pembuka iklan Bukalapak edisi Imlek (Youtube, 2017).

Dari hasil analisis, stereotip yang terbentuk melalui iklan Bukalapak edisi Imlek bukanlah stereotip negatif, melainkan stereotip positif mengenai etnis Tionghoa. Seperti cara etnis Tionghoa berbicara, bahasa dan gaya bahasa yang digunakan, serta perilaku non-verbal etnis Tionghoa. Bovee dan Thil menyatakan bahwa budaya adalah simbol, keyakinan, sikap, nilai, harapan dan norma tingkah laku yang dimiliki bersama (Amanda, 2017). Seperti yang kita tahu bahwa semua etnis-etnis di dunia memiliki budaya-budaya tersendiri. Dalam hal ini, upaya yang dilakukan Bukalapak dalam menarik minat konsumen adalah dengan mengangkat budaya Tionghoa dengan pertimbanga budaya merupakan faktor yang menentukan keinginan dan perilaku seseorang (Aprilia, 2018). Unsur kebudayaan yang bersifat kebendaan seperti bangunan, peralatan, pakaian, dan hasil teknologi lainnya merupakan hasil dari kebudayaan manusia yang tak tampak seperti pemikiran, gagasan, angan-angan, pengolahan pemikiran yang berdampingan dengan nilai-nilai, norma-norma, dan etika yang diwariskan dan dikembagakan oleh manusia (Kristanto, 2008).

Dalam hal konotasi, konotasi dari iklan Bukalapak di atas cenderung bersifat negatif dimana perempuan Tionghoa dicitrakan sebagai perempuan konsumtif. Secara lebih detail, perempuan Tionghoa secara konotatif diposisikan memiliki minat yang kuat dalam membeli barang-barang di market place. Stereotip terhadap etnis Tionghoa merupakan hasil pemikiran yang dialami oleh individu yang kemudian dianggap benar. Oleh karena itu, dapat dikatakan bahwa stereotip yang muncul adalah sesuai dengan indikator stereotip tertentu (Ariasih, 2016). Dalam hal ini, sterotip terbentuk karena tiga faktor penentu. Pertama, karena faktor lingkungan sosial, seperti keluarga dan masyarakat sekitar tempat tinggal. Kedua, karena faktor pengalaman individu yang membentuk stereotip informan. Sebagaimana diutarakan oleh George Kelly, pengalaman tercipta oleh bagaimana cara kita menafsirkan peristiwa dan setiap orang memiliki cara yang berbeda satu sama lain dalam menginstruksi peristiwa. Adapun yang ketiga adalah karena faktor kontak pribadi yang lebih intim (Rumondor, Paputungan \& Tangkudung, 2014). Dalam pandangan penulis, meskipun iklan Bukalapak edisi Imlek dianggap menghadirkan steoretip terhadap etnis Tionghoa, namun demikian promo yang terkandung dalam iklan Bukalapak tersebut terbukti mampu menarik minat mahasiswa yang sedang mencari promo. Dalam hal ini, Bukalapak berhasil menghadirkan daya tarik dalam iklannya. 


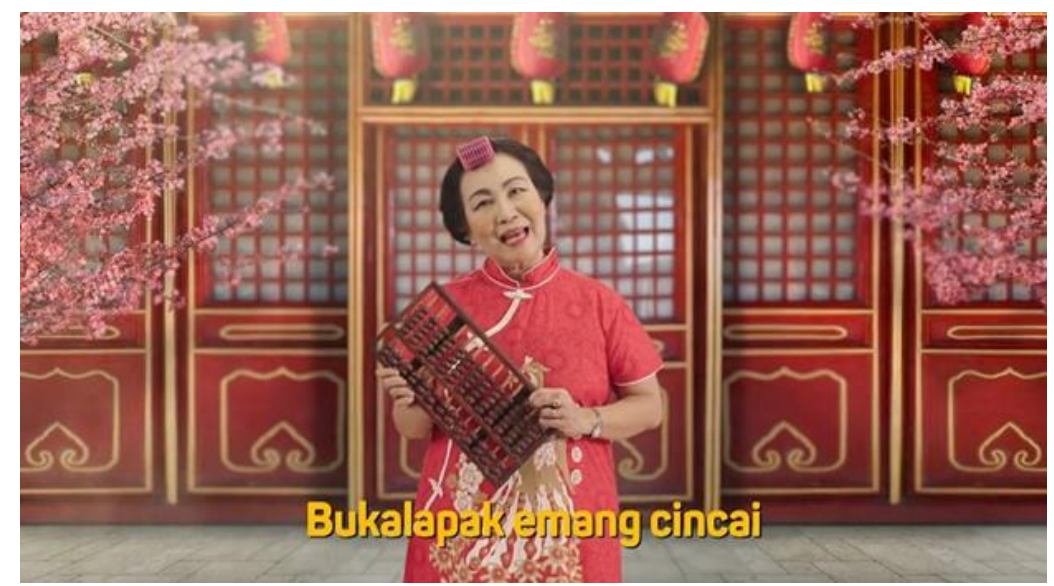

Gambar 3. Adegan ketika tokoh iklan sedang bernyanyi (Youtube, 2017).

Berdasarkan Gambar 3. apabila dicermati dengan seksama terlihat sosok perempuan sedang membawa sempoa atau alat hitung tradisional asal Tiongkok sembari menyanyikan jingle iklan yang mudah diingat oleh khalayak. Ketika tokoh perempuan tersebut melantunkan jingle, secara bersamaan muncul terjemahan di tepi bawah seperti gambar 3. Dalam pandangan penulis, hal tersebut memiliki alasan tersendiri, seperti agar khalayak cepat mengingat lirik jingle. Dalam hal ini, diharapkan ketika seseorang telah terpapar iklan Bukalapak edisi Imlek, maka ia dapat langsung membuka aplikasi Bukalapak. Selain itu, Sementara itu, penggunaan istilah yang sarat akan logat Tionghoa, seperti cincai dan hokcay dicampur dengan bahasa Indonesia menjadi cerminan adanya upaya asimilasi budaya Tionghoa. Berikut lirik jingle yang dinyanyikan oleh tokoh iklan:

\footnotetext{
Bukalapak emang cincai

Harga santai, kagak lebay

Dinego aje say, pasti bisa say

Dinego sampai hokcay

Dinego aja say, pasti bisa say

Dinego sampai hokcay
}

Bercermin dari penelitian-penelitian sebelumnya diantarannya penelitian Khoerunnisa (2019) menunjukkan bahwa perempuan lebih berminat melakukan pembelian online di Bukalapak dibandingkan pria, hal ini karena perempuan ingin mendapatkan produk dengan cara yang mudah dan menghemat waktu sehingga lebih dominan untuk melakukan transaksi online. Adapun usia yang dominan pada penelitian ini adalah berkisar 21-24 tahun. Hal ini menunjukkan bahwa di kisaran usia tersebut, seseorang yang terbiasa menggunakan gadget atau media sosial memudahkan mereka untuk melakukan pembelian secara online. Khoerunnisa (2019) berpendapat bahwa iklan Bukalapak dinilai berpengaruh terhadap minat beli yang dipengaruhi oleh suasana iklan, kesesuaian promo dalam iklan dengan kenyataan, serta peran figur iklan (Khoerunnisa, 2019). Dalam pandangan penulis, tidak menutup kemungkinan, temuan Khoerunnisa (2019) sejalan dengan pendapat penulis tentang konstruksi perempuan konsumtif dalam iklan Bukalapak versi Imlek yang ternyata mampu menarik konsumen karena figur yang ditampilkan menarik.

\section{KESIMPULAN}

Iklan merupakan pesan yang digunakan untuk mendorong, membujuk khalayak ramai agar tertarik pada barang dan jasa yang ditawarkan. Oleh karenanya, pemilik produk atau jasa berlomba-lomba untuk menciptakan iklan sekreatif mungkin agar iklan yang diproduksi berhasil mendapatkan tempat di benak khalayak. Sama halnya dengan iklan Bukalapak versi Imlek yang bernuansa Tionghoa, pada dasarnya iklan tersebut telah membentuk satu stereotip tertentu tentang masyarakat etnis Tionghoa, 
namun demikian dengan gaya yang mudah diingat serta kemasan yang menarik, iklan Bukalapak versi Imlek tersebut sangat berpotensi menarik minat konsumen sebagaimana dijelaskan dalam penelitianpenelitian terdahulu.

\section{PERSANTUNAN}

Terima kasih kepada Dr. Fajar Junaedi yang telah membimbing proses riset dalam mata kuliah Kajian Kritis Iklan di Program Studi Ilmu Komunikasi UMY, selama satu semester genap tahun akademik 2019/2020 yang menghasilkan luaran berupa artikel ini.

\section{REFERENSI}

Aprilia, L. (2018). Efektivitas Iklan Bukalapak Versi Nego Cincai di Youtube dengan Menggunakan Metode Analisa Epic Model pada Mahasiswa STIE PGRI Dewantara Jombang. Disertasi. STIE PGRI Dewantara.

Ariasih, L. P. (2016). Stereotip antara Etnistionghoa dan Etnis Jawa pada Siswa SMA Santa Theresia (Studi Analisis Pendidikan Islam Multikultural). AT-TURAS: Jurnal Studi Keislaman, 3(1), 115 140 .

Harahap, A. S., \& Hussin, S. A. B. S. (2014). Etnik Tionghoa Dibandar Raya Medan: Kajian tentang Pandangan Mereka terhadap Agama Islam. Journal Analytica Islamica, 3(1), 134-151.

Hendro, E. (2013). Multikulturalisme sebagai Model Integrasi Etnis Tionghoa di Indonesia. Sabda: Jurnal Kajian Kebudayaan, 8(1), 34-42.

Khoerunnisa, S. (2019). Pengaruh Efektivitas Iklan Online terhadap Minat Beli Pelanggan Bukalapak (Studi Empiris Iklan Bukalapak Dian Sastro Promo di Setiap Tanggal Kembar). Disertasi. Universitas Bakrie.

Kistanto, N. H. (2008). Sistem Sosial-Budaya di Indonesia. Sabda: Jurnal Kajian Kebudayaan, 3(2).

Kusuma, R., \& Sholihah, Z. (2018). Representasi Etnis Tionghoa dalam Film "Ku Kejar Cinta Ke Negeri Cina" dan "Ngenest". Mediator: Jurnal Komunikasi, 11(2), 165-176.

Lievander, D., Olivia, O., \& Kuo, C. I. (2017). Ritual Perayaan Imlek Etnis Tionghoa Di Kota Toli-toli. Century: Journal of Chinese Language, Literature and Culture, 5(1), 10-17.

Lukitaningsih, A. (2013). Iklan Yang Efektif Sebagai Strategi Komunikasi Pemasaran. Jurnal Ekonomi dan Kewirausahaan, 13(2), 116-129.

Octavianti, T. (2016). Efektivitas Iklan Televisi Bukalapak edisi "Gunakan Jarimu dan Jadilah Pahlawan di Bukalapak” pada Masyarakat Surabaya. Jurnal e-Komunikasi, 4(2).

Rumondor, F. H., Paputungan, R., \& Tangkudung, P. (2014). Stereotip Suku Minahasa terhadap Etnis Papua (Studi Komunikasi Antarbudaya pada Mahasiswa Fakultas Ilmu Sosial dan Politik Universitas Sam Ratulangi). Acta Diurna Komunikasi, 3(2).

Triwijanarko, R. (03 September 2018). Masih Ingat Kampanye Nego Cincai Bukalapak? Seperti Ini Kisahnya. Diakses dari https://marketeers.com/kampanye-nego-cincai-bukalapak/

Youtube. (2017). Nego Cincai Bukalapak. (03 September 2017). Diakses dari https://www.youtube.com/watch?v=S_-mAvCUC_Q 